ethanol and benzalkonium chloride. Opportunities for product substitution were defined as EOI-containing formulations for which an EOI-free product was reported in the survey with identical active pharmaceutical ingredient (API), galenic form and strength.

Results Of 31 invited European countries 20 with 115 NICUs responded. A total of 564 trade names (TN) with 53 APIs were used in more than $10 \%$ of units. EOI containing formulations ( $\mathrm{n}$ = 151) were used for 31 APIs, found overall in 363 TNs. Compared to parenteral forms $(50 / 199 ; 25 \%)$, enteral $(83 / 130 ; 64 \%)$ and topical TNs $(18 / 34 ; 53 \%)$ contained EOI more frequently (OR; 95\% CI 5.3; 3.3-8.5 and 3.4; 1.6-7.1, respectively). An EOI free substitution was available for $31 / 50$ parenteral (63\%), $17 / 83$ enteral (21\%) and 3/18 topical (17\%) TNs. Overall, 51/ 151 (34\%) TNs with EOI could be replaced; substitution was possible in $92 / 151(61 \%)$ of cases if the requirement for identical API strength was ignored.

Conclusions EOI-free formulations available on the European market could be used to reduce the number of TNs with EOI by at least a third.

\section{0-099 THE IMPACT OF BREASTFEEDING ON THE INCIDENCE AND SEVERITY OF NEONATAL ABSTINENCE SYNDROME}

${ }^{1} \mathrm{~K}$ Allegaert, ${ }^{2} \mathrm{JN}$ van den Anker. ${ }^{1}$ Neonatal Intensive Care Unit, University Hospitals Leuven, Leuven, Belgium; 'Intensive Care, Erasmus MC Sophia's Children's Hospital, Rotterdam, Netherlands

\subsection{6/archdischild-2014-307384.166}

Background and aims In light of the current epidemic in the abuse of opioids, a major increase in neonates with neonatal abstinence syndrome (NAS) is likely. Incorporation of breastfeeding as a first pillar of treatment of NAS seems appropriate. We aimed to quantify the impact of breastfeeding on the incidence and severity of NAS.

Methods Pooling of published NAS cohorts, with specific emphasis on the impact of breastfeeding on the incidence (yes/no opioid administration) and duration (duration opioids, duration hospitalisation) of NAS.

Results Three studies [1-3] were retrieved and resulted in a pooled dataset of 400 neonates (218 breastfed, 54.5\%). There is a significant reduction in NAS (54 vs 77\%, number needed to treat 5-6). The same trends are observed when the duration of opioid treatment (difference -18 to -23 days) or the length of hospital stay (difference -4 to -10 days) are considered.

Conclusions Breastfeeding is associated with a clinical significant reduction on both the incidence and the duration of NAS in opioid exposure newborns. Incorporation of breastfeeding as a first pillar of treatment for relieving the NAS symptoms seems to be a very natural, and effective way of addressing this.

\section{REFERENCES}

Abdel-Lalif ME et al. Pediatrics 2006

Wachman EM et al. JAMA 2013

Welle-Strand GK et al. Acta Paediatr 2013

\section{0-100 RELATIONSHIP BETWEEN ADVERSE DRUG REACTIONS AND OFF-LABEL/UNLICENSED DRUG USE IN HOSPITALISED CHILDREN. EREMI STUDY}

${ }^{1}$ KA Nguyen, ${ }^{2} Y$ Mimouni, ${ }^{2} \mathrm{~A}$ Lajoinie, ${ }^{3} \mathrm{~N}$ Paret, ${ }^{2} \mathrm{~S}$ Malik, ${ }^{2} \mathrm{~L}$ Milliat-Guittard, ${ }^{2} \mathrm{~L}$ El-Amrani, ${ }^{2} \mathrm{C}$ Castellan, ${ }^{2} \mathrm{AM}$ Schott, ${ }^{3} \mathrm{~T}$ Vial, ${ }^{2} \mathrm{~B}$ Kassai. ${ }^{1}$ Neonatal Intensive Care Unit and Neonatology, Hospices Civils de Lyon/Hôpital Femme Mère Enfant, Lyon, France; ${ }^{2}$ Clinical Pharmacology, Hospices Civils de Lyon/EPICIME/CIC 1407/Hôpital Femme Mère
Enfant/UMR 5558/CNRS/Lyon 1 University, Lyon, France; ${ }^{3}$ Pharmacovigilance Center of Lyon, Hospices Civils de Lyon/Lyon 1 University, Lyon, France

\subsection{6/archdischild-2014-307384.167}

Background and aim To date few studies have shown a significant association between the off-label drug use and adverse drug reactions.

(ADRs). The main aims of this study are to evaluate the relationship between adverse drug reactions and unlicensed or offlabel drugs prospectively in hospitalised children and to provide more information on prescribing practice, the amplitude, nature and consequences of unlicensed or off-label drug use in paediatric inpatients.

Methods In this ongoing multi-centre prospective study, the French summaries of product characteristics in Theriaque (a prescription products guide) are being used as a primary reference source for determining paediatric drug labelling. Detection of ADRs is carried out by health care professionals and research groups using a trigger tool and patients' electronic health records. The causality between suspected ADRs and medication is evaluated using the Naranjo and the French methods of imputability.

Preliminary results for a 6 month period: $40 \%$ of the 73 detected ADRs were estimated as severe. 1498 patients have been included.

Conclusions This is the first large multi-centre prospective study in France that evaluates the relationship between adverse drug reactions and unlicensed or off-label drugs in hospitalised children. This study will help to identify the risk factors that could be used to adjust preventive actions in children care, guide future research in the field and increase the awareness of physicians in detecting and declaring ADRs. This study is funded by l'ANSM (French national agency of drug security).

\section{0-101 NUMBER OF PROCEDURES AND ANALGESIC THERAPY IN NEONATES ADMITTED TO NICUS: EPIPPAIN 2 STUDY}

R Carbajal ${ }^{1},{ }^{1} \mathrm{E}$ Courtois, ${ }^{2} \mathrm{~S}$ Droutman, ${ }^{3} \mathrm{JF}$ Magny, ${ }^{4} \mathrm{Z}$ Merchaoui, ${ }^{5} \mathrm{X}$ Durrmeyer, ${ }^{6} \mathrm{C}$ Roussel, ${ }^{7} \mathrm{~V}$ Biran, ${ }^{8} \mathrm{~S}$ Renolleau, ${ }^{9} \mathrm{~L}$ Desfrere, ${ }^{10} \mathrm{~F}$ Castela, ${ }^{11} \mathrm{~N}$ Boimond, ${ }^{12} \mathrm{D}$ Mellah, ${ }^{13} \mathrm{P}$ Bolot, ${ }^{14} \mathrm{~A}$ Coursol, ${ }^{15} \mathrm{M}$ El Ayoubi, ${ }^{16} \mathrm{~S}$ Eleni, ${ }^{17} \mathrm{D}$ Brault, ${ }^{18} \mathrm{E}$ Epippain 2 Study Group, ${ }^{19} \mathrm{P}$ Cimerman, ${ }^{20} \mathrm{KJS}$ Anand. 'Emergency Department, Hôpital Armand-Trousseau, Paris, France, ${ }^{2}$ NICU, Hôpital André Grégoire, Montreuil, France; ${ }^{3} \mathrm{NICU}$, Institut de Puériculture Et de Périnatalogie, Paris, France; ${ }^{4}$ NICU, Hôpital Bicêtre, Le Kremlin Bicêtre, France; ${ }^{5}$ NICU, Intercommunal de Créteil, Créteil, France; ${ }^{6}$ NICU, Hôpital Antoine Béclère, Clamart, France; ${ }^{7}$ NICU, Hôpital Robert Debré, Paris, France; ${ }^{8}$ NICU, Hôpital Armand-Trousseau, Paris, France; ${ }^{9} \mathrm{NICU}$, Hôpital Louis Mourier, Colombes, France; ${ }^{10} \mathrm{NICU}$, Intercommunal de Poissy, Poissy, France; ${ }^{11}$ NICU, Hôpital Necker, Paris, France; ${ }^{12}$ NICU, Centre Hospitalier de Meaux, Meaux, France; ${ }^{13}$ NICU, Centre Hospitalier de Saint-Denis, SaintDenis, France; ${ }^{14}$ NICU, Centre Hospitalier René Dubos, Cergy Pontoise, France; ${ }^{15}$ NICU, Hôpital Cochin Port Royal, Paris, France; ${ }^{16}$ NICU, Hôpital Louise Michel, Evry, France; ${ }^{17}$ NICU, Centre Hospitalier Victor Dupouy, Argenteuil, France, ${ }^{18}$ Epippain 2 Study Group, Epippain 2 Study Group, Paris, France, ${ }^{19}$ Centre National de Ressources de Lutte Contre La Douleur, Hôpital Armand-Trousseau, Paris, France, ${ }^{20}$ Department of Pediatrics Critical Care Medecine Division, University of Tennessee Health Science Center, Memphis, USA

\subsection{6/archdischild-2014-307384.168}

Background Neonates admitted to NICUs are frequently subjected to invasive procedures, often with sub-optimal analgesic treatment.

Objective To determine the number of invasive procedures and analgesic practices in NICUs.

Methods Invasive procedures and corresponding analgesic therapies on days 1-14 of NICU admission were prospectively 
Abstract 0-101 Table 1 Five more frequent painful procedures

\begin{tabular}{|l|r|}
\hline \multicolumn{1}{|c|}{ Painful procedure } & \multicolumn{1}{|c|}{ No. (\%) } \\
\hline Nasal aspiration & $11636(28.4)$ \\
\hline Heelstick & $8995(22.0)$ \\
\hline Tracheal aspiration & $8734(21.3)$ \\
\hline Tape removal & $4080(10.0)$ \\
\hline Venipuncture & $1152(2.8)$ \\
\hline
\end{tabular}

studied over a 2-month period in all neonates admitted to the 16 NICUs in the Paris region.

Results For 589 neonates included, mean (SD) gestational age, birth weight, CRIB scores, and number of days of participation were 33.3 (4.5) wks, 1983 (943) gm, 1.5 (2.5), and 7.4 (4.5) days, respectively. 103239 procedures were performed in all neonates, 40927 were classified as painful and 62312 were stressful. The median (range) number of all procedures, painful procedures (PP) and stressful procedures (SP) per infant were, respectively, 124 (0-699), 44 (0-353), and 78 (0-406). Table 1 shows most frequent PP.

Analgesic therapy before PP varied widely among procedures. Analgesic therapy was given before $28.1 \%$ of PP. Continuous infusions of sedatives and/or analgesics were given during $38.8 \%$ of PP. Overall, $61.8 \%$ of PP were performed with an analgesic given before the procedures and/or while the neonate was

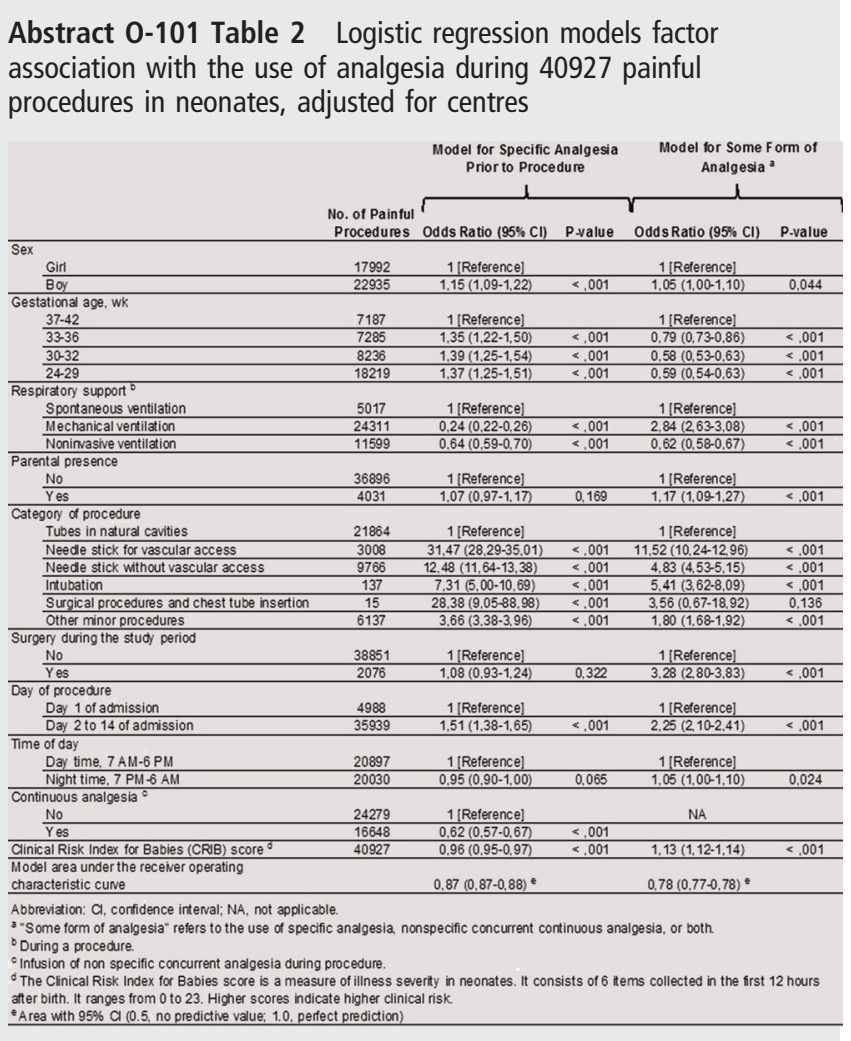

receiving continuous sedation/analgesia. Fig. shows factors associated with preprocedural analgesia use.

Conclusions There is an urgent need to reduce the number of procedures and the pain produced by routine NICU procedures in neonates. Analgesic therapy should be matched with the intensity and duration of acute pain caused by invasive procedures.

\section{0-102 ANALYSES OF CURRENT UNLICENSED AND OFF-LABEL FOR AGE DRUG PRESCRIPTIONS AT A NEONATAL INTENSIVE CARE UNIT}

${ }^{1}$ RB Flint, ${ }^{1}$ SHP Simons, ${ }^{2} \mathrm{DM}$ Burger, ${ }^{3} \mathrm{R}$ de Groot, ${ }^{4} \mathrm{KKM}$ Reiss, ${ }^{5} \mathrm{D}$ Tibboel. ${ }^{1}$ Neonatology, Erasmus University Medical Center - Sophia Children's Hospital, Rotterdam, Netherlands; ${ }^{2}$ Pharmacy, RadboutUMC, Nijmegen, Netherlands; ${ }^{3}$ Pediatrics, Radbout University Medical Center, Nijmegen, Netherlands; ${ }^{4}$ Neonatology, ErasmusMC Sophia Children's Hospital, Rotterdam, Netherlands; ${ }^{5}$ Intensive Care and Pediatric Surgery, ErasmusMC Sophia Children's Hospital, Rotterdam, Netherlands

\subsection{6/archdischild-2014-307384.169}

Background and aims Treatment of critically ill and preterm neonates includes the use of multiple drugs. Many drugs are unlicensed for children or used off-label. Recent changes of drug legislation by FDA and EMA should encourage more drug research in children. We aimed to study the current drugs used in a neonatal intensive care unit.

Methods All drug prescriptions at the level III NICU of Erasmus MC from January 2007 till June 2013 were retrieved from the patient data management system. The product license of each drug was used to judge the label for use in neonatal age.

Results A total of 4,054 neonates (2,240 males) with a median gestational age of $32+0$ (range $23+6-42+2$ ) weeks and a bodyweight at admission of median 1.8 (range 0.36-5.4) kg, were included. Most frequently administered drugs were benzyl-penicillin, gentamycin, caffeine, morphine and surfactant. Of the 24,903 prescriptions, 7,948 (32\%) were off-label for neonatal age, and $1,932(8 \%)$ were unlicensed for children.

Conclusion The availability of adequately licensed drugs still shows important shortcomings. Almost all CNS drugs were offlabel for neonatal age (93\%) although few unlicensed for use in children $(7 \%)$. On the other hand most antimicrobial drugs were on label $(7 \%)$. We believe that drug research in neonates should have high priority to access safe and appropriate medicines.

\begin{tabular}{|c|c|c|c|c|}
\hline \multirow{2}{*}{$\frac{\text { Classification of drugs }}{\text { Antimicrobial drugs }}$} & \multirow{2}{*}{\begin{tabular}{|l|}
$\begin{array}{l}\text { Patient } \\
\text { days }\end{array}$ \\
51,470
\end{tabular}} & \multicolumn{2}{|c|}{ Prescriptionsneonates } & \multirow{2}{*}{$\begin{array}{l}\text { for } \\
\text { Unlicensed } \\
143(1 \%)\end{array}$} \\
\hline & & 10,858 & $761(7 \%)$ & \\
\hline \multicolumn{5}{|c|}{ Central Nervous System } \\
\hline \multirow[t]{2}{*}{ drugs } & 37,796 & 5,100 & $4,720(93 \%)$ & $339(7 \%)$ \\
\hline & & & & 1,375 \\
\hline Haemodynamic drugs & 49,571 & 3,970 & $1,505(38 \%)$ & $(35 \%)$ \\
\hline Respiratory drugs & 43,596 & 3,434 & $608(18 \%)$ & $270(8 \%)$ \\
\hline Endocrinological drugs & 4,215 & 243 & $162(67 \%)$ & $55(23 \%)$ \\
\hline Other drugs & 8,369 & 1,293 & $190(15 \%)$ & $61(5 \%)$ \\
\hline Overall & 195,004 & 24,903 & 7,948 (32\%) & $1,932(8 \%)$ \\
\hline
\end{tabular}

